\title{
JOAN PASQUAL OFM I LA SEVA ADAPTACIÓ TEOLÒGICA DE L'INFERNO*
}

\author{
Francesc J. Gómez \\ Universitat Autònoma de Barcelona \\ FrancescJosep.Gomez@uab.cat
}

I. Joan Pasqual és l'autor d'una extensa summa d'escatologia per a laics dividida en dos volums. El primer, titulat Llibre o Summa de beatitud i conservat actualment en dos testimonis, fou dedicat el 1436 al conseller en cap de la ciutat de Barcelona, Joan Llull i Gualbes, mitjançant un pròleg que definia les dues parts del projecte i manifestava el seu propòsit principal: divulgar entre els laics cultes, però poc familiaritzats amb el llatí, la veritat teològica sobre l'altre món per tal de combatre l'escepticisme ${ }^{\mathrm{I}}$. Curiosament, però, el segon volum d'aquesta summa de novissimis en català, titulat Llibre o Summa de pena i conservat únicament en el manuscrit 468 de la Biblioteca de Catalunya, es completava amb un apèndix $o$ Tractat de les penes particulars d'infern les fonts del qual no eren pas teològiques, sinó poètiques: l'Inferno de Dante, la primera redacció del Comentum de Pietro Alighieri i la tercera redacció del De fabulis poetarum o Ovidius moralizatus de

* El present estudi s'insereix en el projecte FFI2OII-27844-Co3-03 (UAB) finançat pel Ministeri de Ciència i Innovació.

I "Com alguns en aquesta vide present, stans deffallens de rahó e, per instinct diabolical, no considerans la gran dignitat en la qual per benignitat divine són possats, cogiten en lur penças eròneas altre vida no ésser sinó aquesta mortal, la qual dien ésser comuna als bruts e a nós, e sien frustrats de la fi per la qual són creats, per remoure aquests duptes, falçes cogitacions e fantasies diabolicals, mogut de caritat, [2] yo, ffrare Johan Pascal, indigne frare manor de Castelló d'Empúries, del regne de Aragó, la gràcia divina migençant, consider pertractar, no pintant, ne menlevant, ne floregant, ne en bell still possant, com és altre vida sens aquesta mortal [...] [6] Algunament mogut, més avant, fer la dita obra no en latí, mes en romans, per il.luminació de aquells qui per don divinal han lo seu enteniment elevat, jatsia en latí no sien excercitats; [7] majorment per la amistance novelament contracte de vós, molt honorable e de gran prudència insignit mossèn Johan Lull, l'any present, ço és de la nativitat de Jhesuchrist MCCCCXXXVI, conseller digne en cap de la insigníssima ciutat de Barçelona, al qual, per senyal de amor, primer ofer aquest present do, fulcit de la [ $\left.\mathrm{I}^{\mathrm{va}}\right]$ sancta Scriptura, dels dits de doctors cathòlics, actors e de philosofs, suplicant a vós que liberalment, sens càrrega, comunicar lo vullau als de molt gran seviesa dotats senyors ciutadans de la dita ciutat, e a altres, segons vostra sapiència deliberarà. [8] Dividint aquell en dues summes principals, segons que l'altre vide és partida en dues vidas, de glòria e de pena: la primera summa serà de beatitut, la segona serà de pena. Cascuna summa tindrà lo seu volum: lo primer serà appellat Libre de beatitut; lo segon, Libre de pena" (ed. Gómez, 2013, p. 783). 
Pierre Bersuire. Aquest Tractat de les penes particulars d'infern constitueix, per les seves fonts, no solament una peça relativament autònoma dins l'obra de Pasqual, sinó també una aportació molt singular a la literatura europea de divulgació teològica.

Un bon indici d'aquesta singularitat és potser l'extraordinària diversitat de sentits en què s'hi pot aplicar el terme translatio: ultra la transferència d'un saber teològic a un públic laic, que també implica necessàriament un fenomen de transferència lingüística entre llatí i català, l'ús d'unes fonts diguem-ne poètiques en el context d'un tractat teològic comporta, en tercer lloc, una complexa operació de reducció de la ficció poètica a veritat teològica, que a més a més es practica mitjançant operacions de selecció, paràfrasi i/o traducció. Hi podem afegir que el recurs a un repertori mitogràfic per a ús de predicadors com el De fabulis poetarum de Pierre Bersuire insereix Joan Pasqual i el seu Tractat en un capítol molt significatiu de la translatio baixmedieval, atès que el relaciona amb aquella tradició de frares mendicants que Beryl Smalley (1960) qualificà de classicizing friars per llur bona disposició a implicar la cultura clàssica dins el comentari bíblic, la docència teològica i la predicació. Així mateix, l'ús de la Commedia de Dante i del Comentum de Pietro Alighieri en aquest marc teològic converteix el Tractat de Pasqual - "comentarista del Dant" fou el títol amb què el donà a conèixer Ramon d'Alòs-Moner el I92I- en un del testimonis més rellevants de la fortuna dantesca no solament a Catalunya, sinó en el conjunt de la literatura medieval europea, fora d'Itàlia.

Sobre la biografia de Joan Pasqual ${ }^{2}$, avui podem precisar que degué néixer cap a 1388/1390 a Castelló d'Empúries, bisbat de Girona, on prengué l'hàbit franciscà pels volts de 1405 . Més endavant degué residir i estudiar al convent franciscà de Girona, on rebé els quatre ordes menors o acolitat ( 28 de març de I4II), el sotsdiaconat (24 de setembre de I4I2) i el diaconat (I8 de març de I4I3); desconeixem, però, la data en què s'ordenà prevere, no gaire després. Entre el 27 de febrer de I43I i el I3 d'octubre de I 436 consta al convent de Sant Francesc de Barcelona en l'ofici de procurator conventus: Joan Pasqual n'era, doncs, l'oficial més destacat després del guardià i mestre en teologia Genís Puig —un frare obert a la cultura clàssica, a qui el prevere i decretorum doctor Francesc Bertran deixà un Sal-lusti en el seu testament l'estiu de 1438 - , alhora que Nicolau Quilis, traductor del De officiis de Ciceró, n’era la personalitat més il.lustre (Gómez, 2005, 22; 2013, 25-3I). Tant els documents d'aquest període com el pròleg del Llibre de beatitud (I436) s'abstenen d'atribuir a Joan Pasqual el títol de mestre en teologia que l'autor ja

2 El perfil que n'ofereixo tot seguit incorpora algunes dades encara desconegudes en Gómez, 2005, 2I-22, i 20II. Per a un estudi biogràfic extens i documentat, vegeu Gómez, 20I3, I-25 i 794-797. 
ostenta en el breu preàmbul del Llibre de pena, no datat ${ }^{3}$. Sembla, doncs, que Joan Pasqual accedí a la laurea magisterii en l'interval que separa la redacció d'aquests dos volums. En aquest mateix interval també va compondre una altra obra Dels deu manaments, avui perduda però esmentada reiteradament en el Llibre de pena, i s'adonà de la possibilitat d'implicar la Commedia de Dante en la seva pròpia summa de novissimis. Dins la Summa de pena, abans d'arribar al Tractat de les penes particulars d'infern, Pasqual ja fa set referències a Dante — dues al Paradiso i cinc a l'Inferno-, citant-ne versos en l'italià original i reproduint informacions extretes del Comentum de Pietro, mentre que en el Llibre de beatitud no l'esmenta mai. Molt probablement Joan Pasqual no arribà a escriure mai una tercera obra sobre el purgatori que ell mateix anuncia just abans d'emprendre el Tractat de les penes particulars d'infern i que no era prevista en el pròleg de 1436 - una innovació induïda segurament pel model de la Commedia, però potser desestimada més endavant. El 29 de març de I450, Diumenge de Rams, mestre Joan Pasqual predicà a la Seu de Girona un sermó en el qual publicà les solucions d'una disputa mantinguda dies abans amb els jueus de l'aljama en presència de Bernat Joan de Cabrera, comte de Mòdica, havent instat prèviament els jurats de la ciutat a obligar els jueus a assistir a la seva predicació. Tenia aleshores més de seixanta anys, i no en sabem res més, tot i que la seva activitat pública documentada, circumscrita als anys de la lloctinència de la reina Maria, en fa un dels franciscans conventuals més significatius de la generació posterior a la de Nicolau Quilis.

2. El conjunt del Llibre de pena es pot dividir en tres parts principals: la primera estudia la naturalesa del pecat o reatus culpae; la segona, els aspectes de la pena o reatus poenae que són generals i comuns a tots els damnats, mentre que la darrera part, corresponent al Tractat de les penes particulars d'infern - interromput al final del manuscrit després de la rúbrica del capítol LI-, pretén d'explicar les penes particulars que corresponen a cada espècie de pecat. Els dos primers aspectes, que constitueixen pròpiament la Summa de pena, són explicats suficientment mitjançant fonts teològiques estrictes; per contra, Joan Pasqual resol el tercer aspecte assumint com a pròpia l'ordenació moral de l'Inferno de Dante segons l'exposició del Comentum de Pietro Alighieri. L'aportació de Pietro fou, sens dubte, crucial per a l'adopció de l'Inferno com a model: el Comentum explicava els criteris filosòfics i teològics que regeixen la construcció dantesca; posava de manifest la inspiració bíblica, cristiana i clàssica dels seus elements representatius, aportant un ric aparat d'autoritats i loci paralleli, i, finalment, proporcionava al teòleg un bon repertori d'exposicions doctrinals i notícies concretes amb valor exemplar.

3 "[...] jo, frare Johan Pasqual, menor ent[re lo]s mestres en theologia, del ord[e dels] frares menors de la província de Aragó e del convent de Castelló d’Empúries fill [...]” (Gómez, 2013, p. 785). 
De fet, el Tractat de les penes particulars d'infern s'ha de considerar essencialment, no pas una traducció, però sí una adaptació del comentari de Pietro a l'Inferno de Dante: el Comentum de Pietro és la clau de volta fonamental d'una translatio entre la ficció poètica de Dante i el tractat teològic de Pasqual.

Només que, tenint en compte la dimensió poètica i miticofabulosa de l'Inferno de Dante, Joan Pasqual també va decidir d'introduir el seu Tractat amb una secció prèvia, titulada "De las penas comunas segons los poetas", dedicada a exposar al-legòricament els principals elements de la geografia i dels personatges de la mitologia clàssica relatius al més enllà: els rius de l'infern, Caront, Plutó, Prosèrpina, les fúries, les parques, les harpies, Cèrber. Fou per compondre aquesta secció preliminar (especialment els capítols II-X) que Joan Pasqual va acudir a un autèntic manual de mitologia moralitzada per a ús de predicadors com el $D e$ fabulis poetarum de Pierre Bersuire.

Entre els diversos motius que induïren Pasqual a adoptar l'Inferno com a model vertebrador del Tractat de les penes particulars d'infern, crec que se'n poden assenyalar tres d'especialment rellevants des d'un punt de vista teològic (Gómez, 2005, 23-27; 2013, 83-IIO). En primer lloc, el sistema representatiu de la Commedia omple un buit de la literatura teològica estricta, atès que el testimoniatge de l'Escriptura i el magisteri de l'Església no ofereixen prou dades per a bastir una representació teològicament fonamentada de les penes corresponents a cada culpa en particular; fora de la Commedia, Joan Pasqual hauria hagut de recórrer a les descripcions molt més escasses i asistemàtiques de l'infern popular i de la literatura cristiana de visions i viatges ultramundans. En segon lloc, Dante és un poeta cristià que basteix la seva representació del més enllà i la seva classificació dels damnats sobre unes bases filosòfiques i teològiques molt sòlides, que el Comentum de Pietro Alighieri posa perfectament en relleu: la distinció aristotèlica entre incontinència i malícia, la distinció jurídica entre violència i frau, la distinció de pecats contra Déu, contra si mateix i contra el proïsme, o fins i tot l'esquema dels set pecats capitals o mortals. En tercer lloc, la claredat i la solidesa de la construcció escatològica dantesca permet de reduir la complexa multiplicitat de l'univers moral - l'univers de la culpa i de la pena - a una estructura ordenada, capaç de funcionar com un recurs mnemotècnic o una imatge de la memòria ${ }^{4}$. En tenim

4 Ho subratllen Carlo Delcorno (1983, pp. 3-I2) i Frances Yates (1993 [1966], pp. 87-88): "Che l'Inferno di Dante possa essere considerato alla stregua di un sistema mnemonico per fissare il ricordo dell'Inferno e delle sue pene con impressionanti immagini distribuite su una serie ordinata di luoghi [...]. Non è affatto un approccio rozzo o impossibile. Se pensiamo al poema come basato su ordini di luoghi distribuiti in Inferno, Purgatorio e Paradiso, e come a un cosmico ordine di luoghi [...], esso cominicia ad apparirci come una summa di similitudini ed esempi, disposti in ordine e distribuiti su uno sfondo universale [...]. La Divina Commedia diventerebbe così l'esempio supremo della conversione di una summa astratta in una summa di simboli ed esempi, dove la memoria è 
un indici molt significatiu: Joan Pasqual construeix la secció preliminar "De las penas comunas segons los poetas" a partir d'una figura o imago Plutonis que Pierre Bersuire moralitza dins el capítol De formis figurisque deorum amb què ell també introdueix el repertori fabulós de l'Ovidius moralizatus. La familiaritat de Pasqual $\mathrm{amb}$ aquesta tècnica referma la impressió que potser considerà l'estructura de l'Inferno com una vasta summa d'escatologia poètica, capaç d'imprimir-se com a figura o imatge en la memòria del lector: un predicador com ell era, sens dubte, molt conscient de l'eficàcia de les imatges ben estructurades per a la transmissió, la comprensió i la memorització de doctrines compostes de nombrosos elements particulars.

D'altra banda, des d'un punt de vista estratègic, Joan Pasqual degué considerar la poesia de la Commedia, farcida de bones doctrines i d'una multitud d'exemples morals, un al-licient literari de gran seducció per als seus lectors cultes, entre els quals Dante gaudia d'enorme prestigi i autoritat (Gómez, 20I3, 3I-50), alhora que també degué apreciar l'oportunitat de tutelar-ne la lectura proporcionant un model d'interpretació correcta de la ficció dantesca — i de les ficcions dels poetes en general—, discriminant clarament allò que té de vertader a la lletra, allò que requereix una lectura al-legòrica i allò que no pot ésser veritat en cap sentit i que cal impugnar amb arguments teològics.

3. En efecte, Joan Pasqual no obeeix cegament el dictat dels seus models, sinó que els adapta a les seves pròpies intencions compositives i als seus propis criteris teològics's. El primer exemple d'aquesta pràctica es dóna ja en el primer capítol del Tractat, on el teòleg impugna, com a ficció i no vertader, el vestíbul dels pusil-lànimes i dels àngels neutrals del tercer cant de l'Inferno ${ }^{6}$. El cas dels llimbs,

la facoltà che opera questa conversione, formando un ponte tra l'astrazione e l'immagine". Per a la mnemotècnia com a constituent essencial de la retòrica clàssica i medieval, vegeu Caplan, 1970, pp. 196-246; Yates, 1993 [1966], pp. 3-96, i Rivers 2010.

5 De vegades Pasqual retreu a Dante algun presumpte desordre expositiu (Tractat, XXXIV, 2: "E serà tractat de aquests a la mescla, segons Dant axí tracta"; XLII, 2: "E axí, seguint aquest orde, no seguiré l'orde de Dant, qui tot ho mescle, jatsia en molt seguesqua la sua matèria" [cito sempre segons Gómez, 2013]). Però més significatiu és potser el seu comentari de l'episodi en què Dante, introduït per Virgili a la "schiera" d'Homer, Horaci, Ovidi i Lucà, es compta a si mateix "sesto tra cotanto senno" (Inf. IV, IO2): "Si la intenció de Dant posant-se entre aquests és que ell sia en lo nombre e consorci de aquests dampnats, prou li fasse, però he desplaer cum no és dels salvats. Si la sua intenció és que en pohesia sia lo sizè de aquests, és vist a mi que parle ab vanaglòria posar-se ell mateix entre tants hòmens savis, iuxta illud: 'Laus in ore proprio surdescit', jatsia que posant-se sizè de aquests, e no dels primers, pretengua humilitat" (Tractat, XV, I6). Amb una ironia insòlita, Joan Pasqual desbarata l'artifici amb què Dante fingeix humilitat alhora que s'inclou en el cànon dels auctores.

6 Tractat, I, 24: "Açò, emperò, és fictió, car naguna ànima de tals animals no és punida; ne és ver 
que Dante descriu en el quart cant de l'Inferno com un primer cercle infernal, residència comuna dels sants pares, dels infants no batejats i dels infidels magnànims, acumula tants inconvenients teològics que Joan Pasqual en farà tres cercles distints, a més d'interpolar-hi el purgatori com a segon cercle de l'infern (Tractat, XII-XV), aplicant-hi rigorosament un model escolàstic consolidat com a veritat teològica ${ }^{7}$. La subdivisió de les diverses espècies de la incontinència i la malícia -l'alto inferno dels cercles II-V i el basso inferno dels cercles VI-IX o Città di Dite- no planteja inconvenients teològics de tanta envergadura com els llimbs, però l'ordenació dantesca, que Virgili exposa en el cant XI de l'Inferno, tampoc no va satisfer plenament les expectatives de Pasqual, en part per la dificultat de comprendre alguns dels criteris que fonamenten la construcció de Dante, en part per la irresoluble incertesa que envolta alguns elements importants d'aquesta ordenació: primer, el pecat dels damnats a l'Estígia (cercle V); segon, la ubicació no justificada dels heretges al marge superior (cercle VI) de la Città di Dite; tercer, el concepte aristotèlic de bestialitat, que, a diferència de l'oposició entre incontinència i malícia, no té una aplicació segura dins l'esquema de l'Inferno; quart, la distinció interna dels pecats de frau a Malebolge (cercle VIII).

El primer punt es resol sense gaires entrebancs. Pietro Alighieri equipara els quatre cercles de l'alto inferno amb els set pecats capitals segons l'ordre gregorià, identificant a l'Estígia els damnats per accídia, ira, enveja i supèrbia. Malgrat algunes vacil-lacions d'ordre, Joan Pasqual també assumeix l'esquema gregorià i, per tant, divideix aquesta secció de l'infern en set cercles (Gómez, 2013, pp. 210-238).

La confusió que afecta els dos punts següents (Gómez, 20I3, pp. 238-26I) és, en canvi, tan intricada que Pasqual arribarà a proposar dues ordenacions lleugerament discrepants de les culpes de l'infern inferior. La primera (XXXIV, I-3), que oposa els conceptes aristotèlics de malícia i bestialitat, inverteix els cercles VII i VIII de l'Inferno ${ }^{8}$ :

que aquestas ànimas sien fora infern, axí cum Dant fingès; ne és ver que sien alguns àngels qui no són stats rebel-las ne obedients a Déu, car, o són stats rebel.las axí cum los mals, o obeens axí cum los bons". Sobre aquesta qüestió, vegeu Gómez, 2013, pp. I89-193.

7 Tractat, XIV, IO-II: "Item, nota que no stà en veritat que en lo cercle un són los infants no batejats [...] no són hòmens ne dones, per virtuosos que sien nomenats [...]; si no són morts en gràcia de Déu, no són ab aquells los quals nunqua han haüt ús de rahó, e per consegüent són dampnats a doble pena —e de açò no és dupte-, ço és de dan e de sentiment”. Sobre la qüestió dels llimbs, vegeu Gómez, 2013, pp. 193-210.

8 Tractat, XXXIV, I-3: “[...] tota la següent matèria serà de fraudulència, jatsia que algunas són comesas per bestialitat, axí cum tirannia e trahició, blasfèmia e desperació, qui són pijors peccats que aquells qui són fets per malícia solament, en quant bestialitat és pijor que malícia. E serà tractat de aquests a la mescla, segons Dant axí tracta; advertint, emperò, al legidor que quant major és lo peccat de la bestialitat que de malícia, pus pregon en infern és punit; e dels peccats de malícia, aquell qui és pigor pus pregon és punit, e açò matex és dels peccats comesos per bestialitat. E cum 


\begin{tabular}{|c|c|c|c|c|c|}
\hline \multicolumn{2}{|c|}{ Malícia } & \multicolumn{4}{c|}{ Bestialitat } \\
\hline heretgia & frau & tirania & blasfèmia & desesperació & traïció \\
\hline cercle VI & cercle VIII & \multicolumn{3}{|c}{ cercle VII } & cercle IX \\
\hline
\end{tabular}

Per contra, la segona divisió (XL, 6-8) prescindeix definitivament de la bestialitat aristotèlica, substituint-la per la tripartició dantesca de la violència - contra Déu, contra si mateix, contra el proïsme-, i reestructura els cercles VI i VII de l'Inferno incloent l'heretgia entre les violències immediates contra Déu9:

\begin{tabular}{|c|c|c|c|c|c|}
\hline $\begin{array}{c}\text { Contra el } \\
\text { prö̈sme }\end{array}$ & \multicolumn{2}{|c|}{ Contra Déu mediate } & $\begin{array}{c}\text { Contra Déu } \\
\text { immediate }\end{array}$ & $\begin{array}{c}\text { Contra si } \\
\text { mateix }\end{array}$ & $\begin{array}{c}\text { Contra Déu } \\
\text { immediate }\end{array}$ \\
\hline tirania & usura & sodomia & heretgia & desesperació & blasfemia \\
\hline XXXVIII & XXXVII & XXXVI & XXXIV & XXXIX & XXXV \\
\hline VII, girone I & VII, girone 3 & VII, girone 3 & cercle VI & VII, girone 2 & VII, girone 3 \\
\hline
\end{tabular}

Finalment, els dos cercles més profunds de l'infern acullen, com és sabut, dues formes de frau: si no abusa de cap relació de fidelitat correspon a alguna de les deu espècies punides a Malebolge (cercle VIII), mentre que si transgredeix algun vincle de fidelitat correspon a alguna de les quatre espècies de la traïció (cercle IX). Dante i Virgili hi davallen sobre el llom de Geríon, el monstre que Dante presenta com una "sozza imagine di froda» (Inf. XVII, 7). I Joan Pasqual el tractarà, efectivament, com una veritable imago fraudis, perfectament anàloga a les imagines mitogràfiques de Pierre Bersuire. Aprofitant que Pietro Alighieri el descriu com un monstre triforme — cara d'home, cos de serp i cua d'escorpí- i l'interpreta com a tres tipus de fraudulència, el teòleg no solament assumeix literalment aquesta interpretació, sinó que també adopta aquesta tripartició com a criteri ordenador de totes les penes de frau ${ }^{\mathrm{I}}$. L'aplicació d'aquest esquema suposa

la desesperació e la trahició en la última spècia sien peccats de bestialitat pus greus, per ço la trahició és posada pus pregon en infern, tantost ans del cercle de Lucifer. Donchs, açò declarat, tractem del cercle dels heretges, los quals pequen en malícia”.

9 Tractat, XL, 6-8: "Per ço, jatsia que los peccats fets per violència Dant los posa punidors en i cercle —emperò en diversos gerions o statges—, emperò, segons que lo peccat és pus greu, és pigor punit. Jatsia, donchs, hajam posats cascun dels dits peccats en lo seu cercle, no curant de gerió, e hajam primer parlat de la violència pigor, que és inmediatament contra Déu, emperò lo cercle de la tirannia devallant o descendent deu ésser primer tantost aprés del cercle de supèrbia, e aprés lo cercle de la usura, aprés lo cercle de sodomia, aprés lo cercle de heretgia, aprés lo cercle de desperació, aprés lo cercle de blasfemia. Aquesta és la intenció, salvant millor sentència”.

Io Tractat, XLI, I i 4-7: "De la altra spècia de malícia cové tractar, que és frau [...]. Dant afigura 
una profunda reordenació del material que proporcionen l'Inferno i el Comentum. Joan Pasqual prescindeix de les bolge dantesques, assigna un cercle propi a cada espècie de frau -incloent-hi la traïció, tot i que ens manquen els capítols corresponents del Tractat—i els reordena segons un criteri estrictament taxonòmic, que no implica cap progressió de gravetat ${ }^{\mathrm{II}}$ :

\begin{tabular}{|c|c|c|c|c|c|}
\hline & & Tractat & cercle de ... & Inferno & Comentum \\
\hline \multirow[t]{12}{*}{ Geríon } & \multirow[t]{4}{*}{$\begin{array}{l}\text { FRAU COMÈS EN DIT } \\
\text { (HOME) }\end{array}$} & XLII & alcavoteria & bolgia $\mathrm{I}$ & $\begin{array}{c}\text { In Inf. XVIII ad I } \\
\mathrm{i} \text { ad } 2\end{array}$ \\
\hline & & XLIII & adulació & bolgia 2 & In Inf. XVIII ad 3 \\
\hline & & XLIV & $\begin{array}{l}\text { mal consell } \\
\text { (i perjuri) }\end{array}$ & $\begin{array}{c}\text { bolgia } 8 \\
\text { (i bolgia } \mathrm{IO})\end{array}$ & $\begin{array}{l}\text { In Inf. XXVI-XXVII } \\
\text { (i XXIX, I6-I7) }\end{array}$ \\
\hline & & XLV & cisma & bolgia 9 & In Inf. XXVIII \\
\hline & \multirow{5}{*}{$\begin{array}{c}\text { FRAU FET EN LA COSA } \\
\text { (SERP) }\end{array}$} & XLVI & alquímia & bolgia $\mathrm{IO}$ & In Inf. XXIX, 36-46 \\
\hline & & XLVII & moneda falsa, etc. & bolgia Io & In Inf. XXX \\
\hline & & XLVIII & hipocresia & bolgia 6 & In Inf. XXIII \\
\hline & & XLIX & simonia & bolgia 3 & In Inf. XIX \\
\hline & & $\mathrm{L}$ & divinació & bolgia 4 & In Inf. XX \\
\hline & \multirow{3}{*}{$\begin{array}{c}\text { FRAU COMÈS PER OBRA } \\
\text { (ESCORPÍ) }\end{array}$} & - & [barateria] & bolgia 5 & In Inf. XXI-XXII \\
\hline & & - & [furt i lladronici] & bolgia 7 & In Inf. XXIV-XXV \\
\hline & & - & [traïció] & cercle IX & $\begin{array}{l}\text { In Inf. XXXII- } \\
\text { XXXIV }\end{array}$ \\
\hline
\end{tabular}

lo frau a Gerion [...]. Aquest Gerion era dit haver tres còssors per ço cum havia tres regnas o per ço cum frau és divís en dit, cosa e fet (car tot frau o és fet en paraula o en la cosa o en obra). E per ço era finyit ésser en part home, en part stel.lió serpent, en part scorpió. En ço que lo frau és comès en paraula és dit home, car parlar solament pertany al home. És comès lo frau en dit o per alcavotaria o per adulació o per scisma o per mal consell [...]. En ço que lo frau és comès en la cosa és dit stel.lió serpent [...]: axí diversos fraus són fets en les coses, axí cum en las mercaderies, symonias, ypocrisias, divinacions. En ço que lo frau és comès per fet és dit scorpió, lo qual dóna lesió, axí cum són barateries, furts, ledornicis, traÿdors".

II Tractat, XLII, I-3: "Intrant en la matèria de frau, tractarem primer dels cercles de frau comès en paraules, segonament del frau comès en la cosa, tercerament del frau comès en fet. E axí, seguint aquest orde, no seguiré l'orde de Dant, qui tot ho mescle, jatsia en molt seguesqua la sua matèria. Parlant, donchs, del cercle del frau (jatsia Dant en tota la matèria de frau no posa sinó un cercle, lo qual és segons ell vuytè, emperò divisit en moltes búlgies, segons que són moltes spècies de frau: búlgie és 'statge', per ço per aquellas búlgies entenem en lo present 'cercle' o 'statges'), primerament tractarem del frau comès en dit, e primerament del frau comès en alcavotaria e en ruffinaria." 
El Tractat de les penes particulars d'infern pretén d'oferir una divisió exhaustiva de l'univers del pecat, més admissible i ordenada que la construcció poètica dantesca, però basada explícitament en els criteris fonamentals de l'Inferno segons la interpretació del Comentum i en la mesura que són compatibles amb els esquemes teològics més consolidats. Arran d'aquesta translatio teològica, el vestíbul dels pusil-lànimes s'esvaneix en la nebulosa de la ficció; els llimbs o primer cercle de l'Inferno es divideix en quatre cercles d'acord amb la doctrina teològica dels quatre llocs infernals; els cercles II-V es divideixen en els set corresponents a l'esquema gregorià dels pecats capitals; l'heretgia (cercle VI) s'inclou en una reordenació de l'esquema de les violències (cercle VII) segons un criteri de gravetat diferent del de Dante, mentre que les espècies del frau (cercle VIII) i la traïció (cercle IX) es reordenen d'acord amb la divisió tripartida que representa Geríon, la imago fraudis. L'estructura que en resulta no és ja un comentari de l'Inferno, sinó una descripció teològicament plausible de la divisió de la culpa a l'infern cristià. I és en el marc d'aquesta estructura que Joan Pasqual confereix a les penes fictícies de l'Inferno — com a les penes de l'infern mitogràfic - una veritat moral i al-legòrica, com a representació poètica de l'estat de l'ànima culpable en aquesta vida i damnada al més enllà.

\section{BIBLIOGRAFIA}

Alòs-Moner, Ramon d', I92I: "Fra Joan Pasqual, comentarista del Dant", Quaderns d'Estudi, I3, pp. 308-346.

Caplan, Harry, 1970: Of Eloquence. Studies in Ancient and Mediaeval Rhetoric, Ithaca - Londres.

Delcorno, Carlo, 1983: "Dante e l'exemplum medievale”, Lettere Italiane, 35, núm. I (gener-març), pp. 3-28.

Gómez, Francesc J., 2005: “De l'Inferno de Dante a l'infern teològic del framenor castelloní Joan Pasqual”, Mot So Razo, 4, pp. 2I-33

Gómez, Francesc J., 20II: "Joan Pasqual”, a Montserrat Bacardí i Pilar Godayol (dir.), Diccionari de la traducció catalana, Vic, p. 397.

Gómez, Francesc J., 2013: El "Tractat de les penes particulars d'infern" de Joan Pasqual. Estudi i edició critica, tesi doctoral inèdita, Universitat de Girona.

Rivers, Kimberly A., 2010: Preaching the Memory of Virtue and Vice: Memory, Images, and Preaching in the Late Middle Ages, Turnhout.

Smalley, Beryl, 1960: English Friars and Antiquity in the Early Fourteenth Century, Oxford.

Yates, Frances A., 1993 [1966]: L'arte della memoria. Con uno scritto di Ernst H. Gombrich, trad. it. d'Albano Biondi, Torí [Ed. or.: The Art of Memory, Londres]. 